\title{
DA EXCLUSÃO AO SONHO DA CASA PRÓPRIA, UM PANORAMA DO PROGRAMA FNHIS NA CIDADE DE ROCHEDO - MS
}

\section{ARTIGO ORIGINAL}

SOUZA, André Luiz Alvarenga de ${ }^{1}$

MASSUDA, Sabrina Inácio ${ }^{2}$

SOUZA, André Luiz Alvarenga de. MASSUDA, Sabrina Inácio. Da exclusão ao sonho da casa própria, um panorama do programa FNHIS na cidade de Rochedo - MS. Revista Científica Multidisciplinar Núcleo do Conhecimento. Ano 04, Ed. 12, Vol. 01, pp. 67-81. Dezembro de 2019. ISSN: 2448-0959, Link de acesso: https://www.nucleodoconhecimento.com.br/administracao/sonho-da-casapropria

\section{RESUMO}

O estudo verificou como a população da cidade de Rochedo/MS, através de um recorte temporal, respondeu a intervenção social habitacional, que teve como ator principal o Fundo Nacional de Habitação de Interesse Social. A pesquisa foi realizada através de um comparativo do banco de dados entre 2009 a 2013, quando ocorreu o projeto de construção de unidades habitacionais populares e a entrega dessas unidades aos contemplados no município de Rochedo/MS. É preponderante dizer que

1 Doutorado em andamento em Educação. Mestrado em Administração. Especialização em andamento em TEA - Pós Graduação Em Transtorno Do Espectro Autista. Especialização em Educação a Distância. Especialização em MBA Gestão de Pessoas. Graduação em andamento em Licenciatura em Pedagogia. Graduação em Administração. Graduação em Serviço Social. Graduação em Gestão de Recursos Humanos.

2 Especialização em Especialização em Educação a Distância. Graduação em Bacharelado em Psicologia. Graduação em Licenciatura em Psicologia. 
as políticas públicas, são ferramentas das quais o Estado dispõe para intervir na realidade social. No Mato Grosso do Sul, não poderia ser diferente do resto da federação, pois a desigualdade regional se faz presente também. Esta pesquisa tem seus fins relacionados a natureza exploratória, com técnicas quantitativas e qualitativas para interpretação dos dados. Constatou-se que a intervenção mediante aos processos do trabalho técnico social foi de grande valia a comunidade. Concluise a evolução do IDH desta população, trazendo desenvolvimento e esperança de vida para a comunidade.

Palavras-Chave: Técnico social, habitação, políticas públicas, serviço social.

\section{INTRODUÇÃO}

Este estudo visa verificar como a população da cidade de Rochedo/MS, responde a uma intervenção social, que tem como um dos atores principais o Fundo Nacional de Habitação de Interesse Social (FNHIS), que possibilita atender famílias que não possuem renda comprovada ou ainda que vivem de algum tipo de beneficio proporcionado pelas políticas públicas federais, estaduais e ou municipais. A referida pesquisa se deu através de um comparativo do banco de dados já formulado entre os anos de 2009 á 2013, quando ocorreu o projeto de construção, trabalho técnico social e entrega das casas no município de Rochedo MS.

O Brasil passa por uma grande mudança em seu cenário social, está instaurada uma crise política e por consequência a crise econômica que vem corroendo o salário do trabalhador colocando-o em estado de alerta máximo. Diante deste ambiente econômico fragilizado e o grande desejo de adquirir um bem imóvel, todo este cenário coloca o trabalhador assalariado ou ainda aquele que recebe algum tipo de assistência pecuniária social em desarmonia com o anseio em realizar um dos maiores sonhos dos brasileiros, que é ter uma casa própria. Casa própria essa que pode, se tornar apenas uma residência, mas como o sonho é grande, e vai além, transforma-se assim em um lar. Todavia, para que este sonho se torne realidade o Governo tem de proporcionar políticas públicas para viabilizá-lo. Dentre as políticas 
públicas, existentes hoje no Brasil, temos que frisar que as mesmas estão interligadas, e que devem ser por seu caráter social, instrumentos de inclusão e de libertação.

Como podemos observar Nabil Bonduki (1998) destaca a desigualdade social da seguinte forma:

A desigualdade social das cidades brasileiras tem suas causas nas formas com que se organizou a sociedade, em particular, na maneira com que se construiu o Estado Brasileiro, marcado pelo patrimonialismo, no qual se confundem o interesse público e o privado, nas dinâmicas de exploração do trabalho impostas pelas elites dominantes desde a colônia e, principalmente, no controle absoluto dessas elites sobre o processo de acesso à terra, tanto rural quanto urbana. (Bonduki, 1998, p. 56).

Esta posto que na Constituição Federal Brasileira de 1988 que: "São direitos sociais a educação, a saúde, a alimentação, o trabalho, a moradia, o lazer, a segurança, a previdência social, a proteção à maternidade e à infância, a assistência aos desamparados, na forma desta Constituição".

\section{JUSTIFICATIVA E PROBLEMÁTICA}

Mato Grosso do Sul, por tradição, é um estado voltado ao agronegócio e por natureza um estado muito eclético, sendo também um estado rico em extensão territorial o qual tem por vocação a acolhida de vários brasileiros das mais variadas regiões do Brasil e de estrangeiros por fazer fronteira com Paraguai e Bolívia. Na década de 1960 durante o governo de Juscelino Kubitschek (JK) existiu um grande investimento no desenvolvimento industrial culminando na abertura da economia para o capital internacional e com diversas multinacionais se instalando no Brasil. O resultado disso foi um grande êxodo rural que tirou as pessoas de suas casas no interior das cidades, fazendo com que elas fossem até os grandes centros. Os migrantes fugitivos do desemprego foram em busca de trabalho e melhores condições de vida, este processo estendeu-se com força durante as décadas de 70 e 80.

Como foco central da pesquisa, optou-se pela de Cidade de Rochedo/MS por se tratar de uma cidade do interior distante á $74 \mathrm{~km}$ da Capital Campo Grande, que teve um aumento expressivo de população referindo-se ao ano de 2010 com 4.928 habitantes 
para uma estimativa em 2014 de 5.205 habitantes, um aumento de 5,6\% com relação a 2010 IBGE (2010 e 2014) e que recebeu o beneficio do Programa Fundo Nacional de Habitação de Interesse Social (FNHIS) a um grupo de 50 famílias. Estabeleceu-se dentre diversas abordagens a relevância de pesquisar sobre este tema, justificandose que quando consideramos que o ato de morar é intrínseco e ao mesmo tempo um fenômeno indispensável à vida humana. Não obstante, trata-se de um direito humano mundial, garantido e protegido por Convenções Internacionais e pela Constituição Federal Brasileira de 1988.

Os objetivos são mensurar a dinâmica social presente nas famílias envolvidas pósintervenção social no município de Rochedo/MS e avaliar um conjunto de indicadores predeterminados apontando a evolução da família na pós intervenção. Primeiramente realiza-se a caracterização do estudo e apresentam-se as etapas de pesquisa, descrevendo a população e amostra, variáveis estudadas, procedimentos de coleta de dados e técnicas de análise. A presente pesquisa utilizará de métodos quantitativos para obter seus resultados iniciais e finais. Tal abordagem tem o conceito conhecido como positivista e, pós-positivista na atualidade e para Creswell (2007) essa premissa "têm governado as alegações sobre o que garante o conhecimento".

Os dados secundários foram utilizados também para análise da pesquisa e foram obtidos através de órgão federais, livros e artigos que versam sobre programas habitacionais populares de interesse social. Esta pesquisa tem seus fins relacionados á natureza exploratória.

Para Vergara (2007) a investigação exploratória, que não deve ser confundida com leitura exploratória, é realizada em área na qual há pouco conhecimento acumulado e sistematizado. A pesquisa exploratória é de suma importância pois possibilita uma investigação a cerca dos fatos que ainda carecem de mais informações.

A coleta de dados, que desta pesquisa foi um questionário estruturado para as 50 famílias pesquisadas, já a análise e interpretação dos dados coletados se deu através de um comparativo com um banco de dados já existente que foi elaborado no decorrer do projeto entre os anos de, 2010 á 2013. 


\section{POLÍTICA SOCIAL PÚBLICA E O ESTADO}

A política pública remonta os anos 1960 e 1970, surgindo como um subcampo significativo dentro da disciplina de Ciência Política conforme afirma Sabatier (1995) que complementa informando que Daniel Lerner e Harold Lasswell são demostrados por alguns estudiosos como pioneiros em trabalhos sobre a mesma. A partir do momento em que nos colocamos e nos dispomos a estudar a política pública, verificamos as etapas que compõem o processo de formulação das mesmas, nos aprofundamos e conhecemos a principal atividade do Estado, que é preparar as políticas e consequentemente media-las, implementa-las, monitora-las e avalia-las.

Segundo Silva (2014), essa e a parte processual, construída de etapas delimitadas, que racionaliza uma ordem para que possamos ter o mínimo de organicidade no que chamamos de política pública. Primeiramente deve-se observar que a política pública é um conjunto de decisões e não uma decisão isolada, ela se interliga com outras políticas que juntas formam um complexo virtuoso de englobamento social.

Rua (2009) afirma que embora uma política pública implique decisão política, nem toda decisão política chega a constituir uma política pública.

Através de diversos prismas, é primordial estabelecer a necessidade de se conhecer alguns dos diferentes enfoques dados ao significado de política pública. Para compreender e avaliar as políticas públicas e sociais, implementadas por um determinado governo, é fundamental a compreensão de Estado e de Política Pública Social que sustentam tais ações e programas. Dentre inúmeras funções desempenhadas pelo Estado, a função que o mesmo desempenha em nossa sociedade sofreu inúmeras transformações ao decorrer do tempo. Com o aprofundamento e expansão da democracia, as responsabilidades do Estado se diversificaram profundamente diante de todo o contexto sócio-cultural e pela dinamicidade humana, é comum afirmar que a função do Estado é promover a política para o bem-estar da sociedade. 
O Estado é um conceito complexo, histórico e relacional neste sentido Pereira (2008) define o estado da seguinte forma:

O Estado é ao mesmo tempo uma relação de dominação, ou a expressão política da dominação do bloco no poder, em uma sociedade territorialmente definida, e um conjunto de instituições mediadoras e reguladoras dessa dominação, com atribuições que também extrapolam a coerção. Nesse contexto, o governo ganha persona própria, jurídica, separada tanto da persona física do governante quanto da instituição estatal. (PEREIRA, 2008: 148).

O Estado surgiu transversalmente da necessidade de ruptura entre a barbárie e a civilização. Percebe-se que o Estado não existe desvinculado de um processo histórico e nem possui as mesmas características em todos os lugares. As políticas são de responsabilidade do Estado quanto à implementação e manutenção a partir de processo de tomada de decisões que envolvem órgãos públicos e diferentes organismos e agentes da sociedade, relacionada à política implementada. Dentre as etapas que o Estado provém dentro das políticas públicas é importante destacar que o Estado tem o poder de controlá-las, administrá-las e criar métodos e procedimentos para que essas sejam aplicadas. Desta forma, podemos considerar que Políticas Públicas são o Estado em ação, e sobretudo o Estado implantando um projeto de governo, através de programas, de ações voltadas para setores específicos da sociedade. As Políticas sociais implantadas no Brasil tem grande repercussão internacional sendo copiadas por vários países, essas políticas (usualmente entendidas como as de educação, saúde, previdência, habitação, saneamento, etc.) se referem a ações que determinam o padrão de proteção social implementado pelo Estado, visando à diminuição das desigualdades estruturais, produzidas pelo desenvolvimento sócio econômico e dinamizando a política social do país. Não existe divergência significativa quanto à responsabilidade e necessidade de interferência do Estado no processo de combate à pobreza; as discussões concentram-se na forma como o Estado deve efetuar essa intervenção. É fato que as políticas públicas, ferramentas das quais o Estado dispõe para interferir na realidade social e econômica, são justamente onde residem as principais divergências. No Brasil, mais especificamente em Mato Grosso do Sul, não poderia ser diferente do resto do Brasil, pois a desigualdade regional se faz presente em muitos níveis e diferentes dimensões. 
Outro ponto importante que vale resaltar é que a ONU dentro da Declaração Universal dos Direitos Humanos em seu Artigo 25 estabelece que: "toda pessoa tem direito a um padrão de vida capaz de assegurar a si e a sua família saúde e bem estar, inclusive alimentação, vestuário, habitação, cuidados médicos e os serviços sociais indispensáveis (...)" (ONU, 2011).

No Brasil, a Constituição Federal de 1988 é um marco de extrema importante para todo o sistema de proteção social que hoje encontramos estabelecido, mas ainda por decorrência burocrática e pela corrupção, há alguns fatores que podem conjunturalmente ampliar ou reduzir as possibilidades de atendimento aos direitos dos trabalhadores de baixa renda que buscam esse atendimento social na esperança de mudar suas vidas.

De acordo com Ribeiro (2007), é fato que a questão da habitação voltada para os extratos mais empobrecidos das classes subalternas integra as preocupações dos governos brasileiros desde a época imperial.

Sob a ótica da inclusão social e o combate à pobreza, os mesmos devem, necessariamente, passar pela provisão de moradia em condições adequadas para a população em estado de vulnerabilidade social, uma vez que trata-se de um bem de forte impacto na redução da pobreza em qualquer localidade do Brasil. Podemos destacar com ênfase que há importantes documentos de proteção internacional dos direitos humanos como por exemplo o direito à moradia que está previsto na Declaração sobre Assentamentos Humanos de Vancouver (1976), Declaração sobre o Desenvolvimento (1986), na Agenda 21 (1992), e reconhecido como um direito humano em especial na Agenda Habitat adotada pela Conferência das Nações Unidas sobre Assentamentos Humanos, Habitat II26, realizada na Turquia em junho de 1996.

$\mathrm{Na}$ Agenda Habitat II, a primeira menção ao direito à moradia encontra-se no capítulo II referente a metas e princípios como parte do parágrafo 13 , nos termos seguintes:

Nós reafirmamos e somos guiados pelos propósitos e princípios da Carta das Nações Unidas e nós reafirmamos nosso compromisso de assegurar a plena realização dos direitos humanos a partir dos instrumentos 
internacionais, em particular neste contexto o direito à moradia disposto na Declaração Universal de Direitos Humanos, e provido pelo Pacto Internacional de Direitos Econômicos, Sociais e Culturais, [...] levando em conta que o direito à moradia incluído nos instrumentos internacionais acima mencionados deve ser realizado progressivamente $[\ldots]$.

A Agenda Habitat II, documento resultante da Conferência das Nações Unidas sobre Assentamentos Humanos, apresentou como um dos temas globais a "Adequada Habitação para Todos", oferecendo em seu art. 43, o seguinte conceito do que seja adequada habitação:

[...] adequada privacidade, adequado espaço, acessibilidade física, adequada segurança, incluindo segurança de posse, durabilidade e estabilidade estrutural, adequada iluminação, aquecimento e ventilação, adequada infra estrutura básica, bem como o suprimento de água, saneamento e tratamento de resíduos, apropriada qualidade ambiental e de saúde, e adequada locação com relação ao trabalho e serviços básicos devendo todos esses componentes ter um custo disponível e acessível.

Logo o entendimento sobre os direitos humanos, em especial na Agenda Habitat II adotada pela Conferência das Nações Unidas sobre Assentamentos Humanos, nos remete que o direito à moradia deve ser promovido e protegido pelo Estado Brasileiro uma vez que o mesmo estabelece isso em sua Constituição.

Verificasse que os direitos econômicos, sociais e culturais têm eficácia plena, gerando a obrigação imediata ao Brasil para estabelecer as medidas necessárias e efetivar esses preceitos. Contudo as exclusões e intoleráveis injustiças, a tensão social assoma como inevitável, e sob a histórica impunidade tantas vezes pontilhada, vislumbrando quem sabe um dia a verdadeira igualdade entre as classes.

\section{POLÍTICA SOCIAL NA HABITAÇÃO}

Diante da perspectiva de viabilização de políticas públicas habitacionais a mais conhecida hoje é o Programa Minha Casa Minha Vida (PMCMV), criada pela Lei no 11.977 de março de 2009, com a finalidade de promover habitação para a população de baixa renda. Este programa proporciona financiamento habitacional popular com 
juros baixos a famílias com renda mensal de até 10 salários mínimos, que residam em qualquer município brasileiro, proporcionando assim sua inserção ao programa.

Cabe resaltar alguns aspectos históricos sobre a habitação popular no Brasil antes de tudo, na década de 60 que ocorreu pela primeira vez no país, a estruturação de uma política nacional de habitação: a Lei Federal № 4.380 de 21/08/1964 criou o Banco Nacional de Habitação - BNH. Com a deficiência de propostas claras de intervenção no setor habitacional, o BNH é extinto em 1986, passando a ser incorporado pela Caixa Econômica Federal. Com a extinção do BNH, em 1986, o governo federal se ausentou da formulação de uma política pública habitacional que fosse além de programas isolados que sofriam mudanças constantes. Nas décadas 1980, 1990 e início da década de 2000 as favelas apresentaram um crescimento explosivo por decorrência do baixo crescimento econômico e falta de investimento em políticas habitacionais. $\mathrm{O}$ ano de 2005 foi um marco na questão habitacional, foi implantado a nova Política Nacional de Habitação através da Lei no 11.124/2005 que dispõe sobre o Sistema Nacional de Habitação de Interesse Social - SNHIS e em 2006 através da Lei ํo 11.124 criou-se o Fundo Nacional de Habitação de Interesse Social - FNHIS e institui o Conselho Gestor do FNHIS. Este projeto de Lei o qual ficou 13 anos tramitando no congresso nacional, sendo o primeiro Projeto de Lei de iniciativa popular que aguardou o maior número de anos para ser aprovado. Percebe-se que a instituição do Sistema Nacional da Habitação de Interesse Social pode ser considerada um avanço para a política nacional brasileira baseado no fortalecimento da pactuação federativa. O FNHIS esta ligado ao SNHIS e ao PNH (Plano Nacional de Habitação), tanto por reunir recursos públicos destinados a subsidiar moradia às famílias de baixa renda, quanto por definir um modelo de gestão descentralizada que estimula a participação de diversos agentes com vistas à superar o déficit habitacional do país.(BRASIL, 2010 b, p.6).

De acordo com Abiko (1995), o termo "habitação de interesse social", representa um conceito para além da provisão de moradia à população de baixa renda.

O Fundo Nacional de Habitação de Interesse Social (FNHIS) vem de encontro com os interesses de muitas Prefeituras e cidadãos residentes em condições que não são as 
ideais conforme estabelece a ONU e a Constituição Federal do Brasil, neste contexto podemos observar que Matos (2001) indica uma clara definição sobre habitação:

(...) a habitação é vivida e habitada, sendo nesta dupla dimensão que se constrói a sua identidade e a sua própria função social. A habitação satisfaz, na sociedade em que está integrada, um conjunto de funções, como a de abrigo e reprodução da família, sendo, ainda, um elemento fundamental na construção da personalidade individual, de integração social e de socialização, para além de ser um espaço de consumo, de produção de bens e serviços, de ócio e comunicação. (MATOS, 2001, p. 2)

A observação que se pode fazer a cerca do atendimento das necessidades expressas habitacionais das classes trabalhadoras nos conduz a questões complexas e estruturais, relacionadas ao funcionamento das sociedades capitalistas e dela num todo através de um pensamento histórico. A produção habitacional tem uma relação direta com a produção do espaço urbano, que se constitui em elemento primordial para a alocação e bem estar social dos indivíduos, dando lhes dignidade. Observa-se o crescimento demográfico do país, a população urbana que era de 18,8 milhões em 1950 passa para 160,9 milhões de habitantes em 2010 e com uma perspectiva de 220 milhões para 2019.

\section{VULNERABILIDADE FAMILIAR E CONSTRUÇÃO DE INDICADOR SOCIAL FAMILIAR}

O desenvolvimento de índices de desenvolvimento social através de dados censitários vem a cada ano se aperfeiçoando, mas o principal problema desses índices é a grande defasagem em sua janela temporal, deixando de ser realmente uma ferramenta que mostre a verdadeira face social naquele exato ano ou momento. Diante desta perspectiva o estudo apresenta construção do diagnóstico social de 50 famílias beneficiadas pelo FNHIS na cidade de Rochedo no interior de Mato Grosso do Sul. Podemos destacar que a mensuração de dados populacionais é algo histórico e está diretamente ligado ao desenvolvimento do homem em sua plenitude. O Índice de Desenvolvimento Humano (IDH) internaliza variáveis reconhecidas internacionalmente que são de suma importância para as variações no tocante a 
renda per capita e grau de pobreza aplicáveis a contextos mais ou menos desenvolvidos.

Jannuzzi (2003) acrescenta que um indicador social é uma medida em geral quantitativa dotada de significado social substantivo, usados para substituir, quantificar ou operacionalizar um conceito social de interesse teórico (para estudos acadêmicos) ou programático (para formulação de políticas públicas).

Diante aos fatos expostos, destaca-se o conceito de vulnerabilidade diante de indicadores sociais que tem sido muito abordado e empregado em inúmeras situações tornando-se objeto central de outros estudiosos, mas no que se refere a criação de indicadores existe sobretudo um esforço de identificar grupos e espaços (lugares e regiões) vulneráveis e suas causas principais. A avaliação das condições de vida das populações, nos lugares onde elas vivem, continua sendo uma prioridade da análise nas ciências sociais aplicadas, mesmo quando tudo indica que a exclusão econômica é maior que a inclusão Garcia; Matos (2007).

O Brasil é um país de grandes extensões territoriais e concentra populações com as mais distintas culturas e condições socioeconômicas, tais fatores corroboram para que o país apresente um quadro de desigualdade social significativo.

Constitui lugar comum afirmar que o Brasil é um país caracterizado por desigualdades. (...) o problema dos desequilíbrios do país cita o desequilíbrio entre indivíduos (...) e o desequilíbrio entre regiões, vale dizer, o problema da desigualdade inter-regional de renda. (PESSOA, 2001).

Diante a apresentação conceitual sobre vulnerabilidade familiar e construção de indicador para a medição da evolutividade familiar, podemos afirmar que um indicador tem a perspectiva de ampliar os conceitos abstratos, transformando-os em números. Frente a esses aspectos definiu-se três dimensões básicas para o indicador que foram: educação, renda e habitação. Diante da formulação de um indicador que avalia os índices de inserção social é fundamental entender que a abrangência familiar dos resultados são informações valiosíssimas. 


\section{HISTÓRICO DE ROCHEDO}

De acordo com IBGE, Censo demográfico 2010, a formação do Povoado de Rochedo teve início em 1931, quando uma leva de nordestinos, especialmente baianos, alagoanos e pernambucanos, acampou à margem direita do Rio Aquidauana, na tentativa de descobrir possíveis mochões diamantíferos a exemplo do que já vinha ocorrendo no percurso daquele rio. Os esforços daquela gente, depois de exploração em exploração, foram compensados pela descoberta de rica jazidas de diamantes. Posteriormente os remanescentes desse povoado voltaram sua atenção para a agricultura, a pecuária e a extração da madeira.

A história de Rochedo é muito interessante, mas seus aspectos humanos e sociais deixam muito a desejar no que se refere á dignidade da pessoa humana, pois é um município pobre com poucos empregos e oportunidades. Podemos observar que o município também tem um expressivo déficit habitacional por se tratar de um município com menos de 10.000 (dez mil) habitantes. Conforme dados do Censo IBGE 2010, a população total do município era de 4.928 residentes, dos quais 152 encontravam-se em situação de extrema pobreza, ou seja, com renda domiciliar per capita abaixo de $R \$ 70,00$. Isto significa que $3,1 \%$ da população vivia nesta situação. Do total de extremamente pobres, $86(56,7 \%)$ viviam no meio rural e 66 (43,3\%) no meio urbano. O Censo também revelou que no município havia 17 crianças na extrema pobreza na faixa de 0 a 3 anos e 3 na faixa entre 4 e 5 anos. $O$ grupo de 6 a 14 anos, por sua vez, totalizou 18 indivíduos na extrema pobreza, enquanto no grupo de 15 a 17 anos havia 18 jovens nessa situação. Foram registradas 12 pessoas com mais de 65 anos na extrema pobreza. Esses dados corroboram ainda mais para a pesquisa, pois mostram uma realidade social através de um prisma de um instituto oficial do governo. O estudo vem de encontro com anseios da grande maioria das populações que vivem a margem da sociedade, na exclusão social diante a sua face habitacional. Podemos observar a gritante fragilidade social das pessoas que estão em idades de extrema produção que vai de 18 a 59 anos, totalizando $55,5 \%$ da população. Do total de extremamente pobres no município, 76 são mulheres (49,7\%) e 77 são homens (50,3\%). Do total da população em extrema pobreza do município, 49 (32,2\%) se classificaram como 
brancos e $103(67,8 \%)$ como negros sendo que $17(11,2 \%)$ se declararam pretos e 86 $(56,6 \%)$ pardos. Um dado também que chama muito a atenção com relação a inclusão e exclusão social é que de acordo com o censo 2010, havia - indivíduos extremamente pobres com alguma deficiência mental; 13 tinham alguma dificuldade para enxergar; 6 para ouvir e 9 para se locomover.

Outro dado espantoso do município levantado pelo CENSO 2010 foi a escolaridade dos indivíduos os quais, das pessoas com mais de 15 anos em extrema pobreza, 15 não sabiam ler ou escrever, o que representa $14,7 \%$ dos extremamente pobres nessa faixa etária. Dentre eles, 12 eram chefes de domicílio. Dentre outros dados levantados pela mesma pesquisa em 2010 foi que no município havia 17 crianças de 0 a 3 anos na extrema pobreza não frequentando creche, o que representa 100,0\% das crianças extremamente pobres nessa faixa etária. Entre aquelas de 4 a 5 anos, havia 03 crianças fora da escola $(100,0 \%$ das crianças extremamente pobres nessa faixa etária) e, no grupo de 6 a 14 anos, eram 03 (17,1\%). Por fim, entre os jovens de 15 a 17 anos na extrema pobreza, 03 estavam fora da escola $(17,7 \%$ dos jovens extremamente pobres nessa faixa etária). Outra informação que também se enquadra em um nível de relevância importante, esta relacionado aos equipamentos sociais, tais como eletricidade, água, esgoto, coleta de lixo e quantidade de banheiros no domicilio, o CENSO 2010 é que 3 pessoas extremamente pobres (2,0\% do total) viviam sem luz, 27 pessoas (17,5\%) não contavam com captação de água adequada em suas casas, 128 pessoas $(84,0 \%)$ não tinham acesso à rede de esgoto ou fossa séptica e 90 pessoas $(58,9 \%)$ não tinham o lixo coletado e com relação a quantidade de banheiros no domicilio 6 pessoas extremamente pobres ( $4,0 \%$ do total) não tinham banheiro em seus domicílios.

Através desses dados podemos fazer um comparativo referente ao banco de dados fornecidos pela empresa Triady Consult, relacionado a um grupo de 50 famílias da cidade de Rochedo - MS a qual foi beneficiária de um programa social de habitações populares no ano de $2013 \mathrm{com}$ a entrega de 50 casas que atendeu um grupo de 50 famílias totalizando um número de intervenção referente a 163 pessoas, tirando essas famílias da pobreza extrema e dando-Ihes dignidade. O Trabalho Técnico Social é o 
conjunto de ações que visam promover a autonomia e o protagonismo social, planejadas para criar mecanismos capazes de viabilizar a participação dos beneficiários nos processos de decisão, implantação e manutenção dos bens/serviços, adequando-os às necessidades e à realidade social.

Através da pesquisa de campo realizada com $100 \%$ da população beneficiada para compor o trabalho técnico social, entre os anos de 2010 e 2011 foi sintetizado os seguintes dados:

- A população é composta por $94 \%$ do sexo Feminino Chefes de Família, $6 \%$ do sexo Masculino, 2\% de Portador de Necessidade Especial/Deficiente e 8\% de idosos.

- Em relação a idade a população é predominantemente adulto-jovem, com $23 \%$ até 25 anos, $21 \%$ entre 26 a 30 anos, 22\% entre 31 a 40 anos, 18\% entre 41 a 50 anos, $10 \%$ entre 51 a 60 anos e $6 \%$ acima de 60 anos de idade.

- Do Estado Civil, $36 \%$ da população é solteiro, $26 \%$ é amasiado, $22 \%$ casado, $8 \%$ separado, $4 \%$ divorciado, $2 \%$ viúvo e $2 \%$ união estável.

- A composição familiar da população beneficiada é composta da seguinte forma: $32 \%$ da população moram com 02 pessoas na casa, 22\% moram com 03 pessoas, outros $22 \%$ moram com 04 pessoas, $10 \%$ moram com 05 pessoas, $6 \%$ moram com 06 pessoas e $2 \%$ moram com 07 pessoas e $6 \%$ moram sozinhos. Também constatamos que $32 \%$ da população possuem 02 filhos que moram juntos, 26\% possuem 01 filho que moram juntos, 26\% possuem 03 filhos que moram juntos, $04 \%$ possuem 03 filhos que moram juntos e $12 \%$ não possuem filhos que moram juntos.

- Da escolaridade, $18 \%$ são alfabetizados, $48 \%$ possuem o Ensino Fundamental Incompleto, 2\% o Ensino Fundamental Completo, 2\% possuem o Ensino Médio Incompleto, 24\% o Ensino Médio Completo e 6\% o superior completo.

- A renda familiar mensal dos beneficiários é de baixa renda, a maioria não recebe a quantia de um salário mínimo, $46 \%$ tem renda familiar mensal de $\mathrm{R} \$ 100,00$ a $\mathrm{R} \$ 500,00,32 \%$ de $\mathrm{R} \$ 501,00$ a $\mathrm{R} \$ 700,00,16 \%$ de $\mathrm{R} \$ 701,00$ a $\mathrm{R} \$$ $1.000,00$. Quanto a situação socioeconômica da população beneficiada estão 
$26 \%$ desempregados, $50 \%$ são autônomos, $26 \%$ estão empregados, $4 \%$ são aposentados.

- A Secretaria de Assistência Social do Município de Rochedo informou que os beneficiários das unidades habitacionais participam de programas sociais, sendo $64 \%$ participam dos programas e $36 \%$ não participam.

- No aspecto habitacional, $25 \%$ dos beneficiários moram em casa cedida/emprestada, e 25\% em casa alugada.

- Como meio de transporte utilizam bicicleta, já que o município não possui transporte coletivo e nenhum dos beneficiários possuem carro ou moto.

Podemos caracterizar que estes dados obtidos entre os anos de 2010 e 2011 refletem a realidade temporal daquela época em que ainda não haviam recebido as 50 Unidades Habitacionais de Interesse Social.

\section{CONSIDERAÇÕES FINAIS}

Diante todo cenário apresentado pela pesquisa, constatou-se que a intervenção mediante todos os processos do trabalho técnico social foi de grande valia a comunidade. Os dados obtidos pós ocupação, compõe um banco de dados fabuloso, onde nos mostra a evolução do IDH desta população, trazendo a luz do desenvolvimento e de uma nova esperança de vida para a comunidade. Foi realizado vistoria de pós ocupação em 44 as 50 unidades habitacionais na data de 20/07/2014, as 06 casas que não foram visitadas encontravam-se fechadas, mas todos os 50 beneficiários já se mudaram para as unidades habitacionais. Na visita responderam ao questionário de visitas em que se encontra tabulado nas próximas páginas e assinaram lista de visita de pós-ocupação, em que se encontra anexo a este relatório. Todos os objetivos propostos no PTTS foram cumpridos, em que todas as atividades propostas no PTTS foram desenvolvidas com eficiência e eficácia. No desenrolar do desenvolvimento do projeto deparamo-nos com situações positivas de conquistas, em que os beneficiários se mostravam entusiasmados e ativamente participativos com os temas das campanhas educativas, oficinas e cursos de geração de renda. Cada encontro era motivador ver e sentir cada pessoa entregue com entusiasmo, olhos brilhantes e relatos de ajuda na vida de cada um, foi muito gratificante. 
Os desafios encontrados podemos dizer que foi na época de campanhas políticas, quando houve eleição para prefeito surgiam muitos boatos de que os beneficiários que não fossem do partido tal não seriam contemplados com as casas, com isto tivemos muitas conversas e reuniões esclarecedoras com os beneficiários para entenderem o real funcionamento do programa e desmistificar tais boatos. A metodologia escolhida em cada etapa foi adequada e atendeu aos objetivos propostos nas atividades. A comunidade envolveu-se e foi muito motivador o retorno para equipe dos técnicos sociais envolvidos, profissionais e parceiros envolvidos também responderam a nossas expectativas com ajuda e grandes parcerias. Um ponto muito importante levantado dentro das reuniões com os mutuários beneficiários do programa, foi o tamanho das casas, pois em se tratando de famílias com grau de instrução bem deficitários, muitos possuem um número elevado de filhos, o que dentro das casas fornecidas pelo programa acabam sendo pequenas para acomodar toda a família.

O ponto de melhoria apresentado pelos mutuários beneficiários do programa foi que o tamanho do terreno é ótimo, mas o tamanho da casa precisa ser revisto. Diante toda a sistematização do trabalho exposto vale ressaltar que na Agenda Habitat II, documento resultante da Conferência das Nações Unidas sobre Assentamentos Humanos, apresentou como um dos temas globais a "Adequada Habitação para Todos", oferecendo em seu art. 43.

Finalizando este trabalho, podemos salientar de forma clara que a questão da moradia é um dos fatores preponderantes para a dignidade da pessoa enquanto cidadã e de sua família, através deste olhar tão peculiar e diante nos novos desafios a serem enfrentados com constantes cortes de verbas públicas para os projetos sociais a de se pensar em novas estratégias para a melhora da qualidade de vida da população em estado de vulnerabilidade social.

\section{REFERÊNCIAS}

ABIKO, Alex. Introdução à Gestão Habitacional. São Paulo: EPUSP Departamento de Engenharia de Construção Civil, 1995. 
BONDUKI, Nabil. Origens da habitação social no Brasil: arquitetura moderna, lei do inquilinato e difusão da casa própria. São Paulo: Estação Liberdade, 2004.

BONDUKI, Nabil. Política habitacional e inclusão social no Brasil: revisão histórica e novas perspectivas no governo Lula. 2008.

CRESWELL, J. W. Projeto de Pesquisa. Porto Alegre: Artmed, 2010.

GARCIA R. A. e MATOS R.; Mensurando a inserção social dos migrantes brasileiros; Unicamp; 2007; $<$ <ttp://biblioteca.ibge.gov.br/visualizacao/dtbs/matogrossodosul/rochedo.pdf>, acesso em (07/05/2015).

JANNUZZI, P. M. Indicadores sociais no Brasil - Conceitos, Fontes de dados e Aplicações. Alínea: Campinas, 2003.

MATOS, Fátima Loureiro de. A Habitação no Grande Porto: uma perspectiva geográfica da evolução do mercado e da qualidade habitacional desde finais do séc. XIX até o final do milénio. 2001. Tese (Doutoramento em Geografia) Universidade do Porto, Porto, 2001.

MINISTÉRIO das cidades <http://www.cidades.gov.br/index.php/sistema-nacionalde-habitacao-de-interesse-social-snhis.html>, acesso em (07/05/2015).

ORGANIZAÇÃO DAS NAÇÕES UNIDAS - ONU. Declaração Universal dos Direitos Humanos. 1948. Disponível em: <www.direitoshumanos.usp.br >, Acesso em: 31 julho. 2015.

PEREIRA, P. A.P. Política Social e Democracia. 2. ed. Rio de Janeiro: Cortez, 2008.

RIBEIRO, Edaléa Maria, A POLÍTICA DE HABITAÇÃO POPULAR NO BRASIL EM TEMPOS DE GLOBALIZAÇÃO NEOLIBERAL. III JORNADA INTERNACIONAL DE POLÍCAS PÚBLICAS QUESTÃO SOCIAL E DESENVOLVIMENTO NO SÉCULO XXI, 2007. 
RUA, Maria das Graças. Políticas Públicas. Florianópolis: Departamento de Ciências da Administração / UFSC, 2009. 130 p.

SILVA, Jose Irivaldo Alves Oliveira Formulacao de politicas publicas / Jose Irivaldo Alves OliveiraSilva. - Florianopolis : Departamento de Ciencias da Administracao IUFSC, 2014.Portal

Participar <http://www.participa.br/articles/public/0007/9445/Agenda_Habitat_para_ Munic_pios_Brasil.pdf>, acesso em (07/05/2015).

. Lei Federal 11.124, de 16 de junho de 2005. Dispõe sobre o Sistema Nacional de Habitação de Interesse Social - SNHIS, cria o Fundo Nacional de Habitação de Interesse 15 Social - FNHIS e institui o Conselho Gestor do FNHIS. Disponível em <www.cidades.gov.br>, acessado em (Agosto de 2015).

Enviado: Outubro, 2019.

Aprovado: Dezembro, 2019. 